\title{
Genetic diversity and antifungal susceptibility of Candida albicans isolates from Iranian HIV-infected patients with oral candidiasis
}

\author{
Iradj Ashrafi Tamai, Babak Pakbin * (10 and Bahar Nayeri Fasaei
}

\begin{abstract}
Objective: The objectives of this study were to investigate the antifungal susceptibility and genetic diversity of Candida albicans isolated from $\mathrm{HIV}^{+}$patients with oropharyngeal candidiasis. A total of $50 \mathrm{C}$. albicans isolates were cultured on Sabouraud glucose agar containing chloramophenicol. The antifungal susceptibility of the isolates against fluconazole, clotrimazole, nystatin, amphotericin B, ketoconazole and flucytosine was assessed using disc diffusion method. The genetic diversity of $C$. albicans isolates was determined using random amplified polymorphic DNA marker.

Results: The inhibition zones ranged from $4 \pm 1.8$ to $40 \pm 3.8 \mathrm{~mm}$ for fluconazole, $7 \pm 1.0$ to $37 \pm 1.8 \mathrm{~mm}$ for ketoconazole, $14 \pm 0.8$ to $24 \pm 0.8 \mathrm{~mm}$ for amphotericin B, $25 \pm 0.0$ to $33 \pm 0.0 \mathrm{~mm}$ for nystatin and $7 \pm 4.2$ to $40 \pm 0.0 \mathrm{~mm}$ for clotrimazole. At $90 \%$ similarity, three distinct groups were observed. The smallest cluster composed of 3 isolates, whereas the largest one composed of 17 isolates. 32\% (16/50), 28\% (14/50) and 14\% (7/50) were resistant to fluconazole, ketoconazole and clotrimazole, respectively.
\end{abstract}

Keywords: Candida albicans, HIV ${ }^{+}$patients, Genetic diversity, RAPD-PCR, Antifungal susceptibility

\section{Introduction}

Candida albicans (C. albicans) has been known as one of the most important clinical pathogen [1]. Oropharyngeal candidiasis (OPC) is frequently because of the increase of predisposing factors such as hematologic malignancy, acquired immunodeficiency syndrome (AIDS), Nezelof syndrome, zinc and iron deficiency. OPC, as the independent predictor of immunodeficiency in AIDS patients, increases the mortality and morbidity among these patients; consequently, it requires prompt therapy and precise diagnosis [2]. C. albicans, only species recovered from up to $70 \%$ of HIV-infected individuals, is one

*Correspondence: b.pakbin@ut.ac.ir

Department of Microbiology and Immunology, Faculty of Veterinary

Medicine, University of Tehran, P.O. Box: 14155-6453, Tehran, Iran of the most common cause of mucosal yeast infection in human [3]. The prevalence of oral Candida infections in patients with HIV has recently been decreased. Two factors described this phenomenon; first, overuse of antifungal agents, particulary azole antibiotics; second, the introduction of highly active antiretroviral therapy resulted in a significant decrease in the incidence of opportunistic diseases and the mortality of AIDS [4]. Since azoles, particularly fluconazule, have been used for prophylaxis or treatment of AIDS, resistance to this antifungal agent is concerning [5]. Resistance can be acheived by an alteration of the target enzyme, the cytochrome P-450 lanosterol $14 \alpha$-demethylase, mediated by ERG11 gene, or the failure of azole antifungal to accumulate inside the cell as a result of enhanced drug efflux, mediated by MDR and CDR genes [6]. 
Recent progresses in molecular typing methods have been generated by several techniques based on PCR, including multi-locus enzyme electrophoresis (MLEE), restriction enzyme analysis (REA), randomly amplified polymorphic DNA (RAPD) analysis and karyotype analysis for evaluation of genetic diversity and molecular epidemiology [7]. In recent years, RAPD has been increasingly employed as a molecular method for investigation of population genetics and genotyping of different microorganisms [8]. The genetic diversity of various Candida species and the correlation between the antifungal susceptibility and gene diversity have previously been studied. The RAPD assay relies on the use of arbitrary primers that are annealed to DNA. This technique has become one of the most commonly used methods for DNA fingerprinting of clinical Candida species [9]. The purposes of the present study were to determine the antifungal susceptibility and the genetic diversity of C. albicans isolates collected from oral cavity of Iranian $\mathrm{HIV}^{+}$ patients with OPC.

\section{Main text \\ Microorganisms}

This study was performed on 50 C. albicans isolates collected from oral cavity of $\mathrm{HIV}^{+}$patients, from October to November 2011, at the AIDS Research and Training Center of Imam Khomeini Hospital, Tehran, Iran. HIVinfected Patients, previously diagnosed and confirmed with ELISA test, with the age between 15 and 65 years old and including both genders, were enrolled for the study and referred to the hospital to receive medical advice and health care. They had not any systemic diseases and did not receive any antifungal therapy during the last 3 months; however, they were under treatment for HIV. All confirmed HIV-infected patients with oropharyngeal lesions were included in the study. The most likely potential confounding factors were having systemic diseases and receiving antifungal treatment which were considered to minimize the effects of possible confounding factors. For the collection of speciemens, oral swabs were collected from the lesions with a sterile swab. We used a wet mount with $10 \% \mathrm{KOH}$ preparation and Giemsa stain for microscopic examination of pseudohyphae and yeast cells. All swab samples were cultured on Sabouraud glucose agar (SGA; 20 g/l glucose, $10 \mathrm{~g} / \mathrm{l}$ peptone, $20 \mathrm{~g} / \mathrm{l}$ agar, $\mathrm{pH}$ 5.6) containing $0.05 \%$ chloramphenicol (Merck Co., Darmstadt, Germany). The cultures were incubated at $37^{\circ} \mathrm{C}$ and examined daily for 1 week. Identification of $C$. albicans isolates were performed on the basis of germ tube test, colony color on CHROMagar (Paris, France Company), sugar fermentation, assimilation tests by RAPID yeast plus system (Remel Inc., USA). We employed internal transcribed spacer primer pairs including CALB1 and CALB2. Also, we used C. albicans ATCC 90028 as the positive control in this study.

\section{Antifungal susceptibility}

Antifungal susceptibility of the isolates were determined using agar disc diffusion assay according to Clinical and Laboratory Standards Institute (CLSI) document M44A2 [10]. Six standard antifungal discs including fluconazole $(25 \mu \mathrm{g} /$ disc $)$, clotrimazole $(10 \mu \mathrm{g} /$ disc $)$, nystatin (50 $\mu \mathrm{g} /$ disc $)$, amphotericin B (20 $\mathrm{g} / \mathrm{disc})$, ketoconazole $(10 \mu \mathrm{g} /$ disc $)$ and flucytosine $(1 \mu \mathrm{g} /$ disc $)$ were obtained from Oxoid (Hampshire, UK) [11]. Briefly, a suspension of C. albicans $\left(10^{6} \mathrm{cell} / \mathrm{ml}\right)$ was spread onto Muller-Hinton agar (Oxoid, Hampshire, UK) plates containing $2 \%$ glucose and $0.5 \mu \mathrm{g} / \mathrm{ml}$ methylene blue dye. Antifungal discs were placed on the inoculated plates. These plates were incubated $48 \mathrm{~h}$ at $37{ }^{\circ} \mathrm{C}$. The diameter of the inhibition zones was measured in millimeter [12].

\section{DNA extraction}

All samples, which were not treated with the antifungal drugs, were cultured on SGA at $37{ }^{\circ} \mathrm{C}$ for $48 \mathrm{~h}$. Genomic DNA of yeast cells was extracted as previously described [13] and purified using a commercial DNA purification kit (Ultraclean Microbial DNA Isolation kit, MO BIO, USA) according to manufacturer's structure. DNA concentration and purity were determined based on optical density at $260 \mathrm{~nm}$ and ratio OD 260/280 nm, respectively.

\section{PCR assay and RAPD}

PCR analysis was performed with the oligonucleotide primers CALB1: TTTATCAACTTGTCACACCAGA and CALB2: ATCCCGCCTTACCACTACCG (The GenBank accession number refers to primers L47111, L28817) [14]. Amplification reactions were done in a final volume of $25 \mu \mathrm{l}$ containing $2.5 \mu \mathrm{l}$ of reaction buffer $(10 \times)$, $1.5 \mathrm{mM} \mathrm{Mgcl}_{2}(50 \mathrm{mM}), 0.2 \mathrm{mM}$ dNTP $(10 \mathrm{mM}), 0.5 \mu \mathrm{M}$ (each) primers, $0.5 \mathrm{U}$ of Taq DNA polymerase, $2 \mu \mathrm{l}$ of genomic DNA template and deionized sterilized water to the final volume. Amplification was carried out using a Techne Tc-512 thermo cycler (Techne, UK). Initial denaturation was at $96{ }^{\circ} \mathrm{C}$ for $5 \mathrm{~min}$, as follows: 35 cycles of $30 \mathrm{~s}$ for denaturation at $94{ }^{\circ} \mathrm{C}, 30 \mathrm{~s}$ for annealing at $55^{\circ} \mathrm{C}$ and $30 \mathrm{~s}$ primer extension at $72{ }^{\circ} \mathrm{C}$, followed by a terminal extension at $72{ }^{\circ} \mathrm{C}$ for $15 \mathrm{~min}$. The PCR products were electrophoresed on $1.5 \%$ agarose gel for $1 \mathrm{~h}$ at $80 \mathrm{v}$ and stained with ethidium bromide $(2 \mu \mathrm{g} / \mathrm{ml})$. RAPD-PCR was performed with RSD12: 5'-GGTCCGTGTTTCAAG ACG-3' primer [15]. Each reaction mixture contained $2.5 \mu \mathrm{l}$ of reaction buffer $(10 \times), 2.5 \mathrm{mM} \mathrm{MgCl}, 200 \mathrm{mM}$ dNTPs mix, $1.25 \mu \mathrm{M}$ of primer RSD12, $1 \mathrm{U}$ of Taq DNA polymerase and 100-400 ng of DNA template in final reaction volume of $25 \mu \mathrm{l}$. PCR amplification program for 
RSD12 primer involved 1 cycle at $95{ }^{\circ} \mathrm{C}$ for $5 \mathrm{~min}$, then 40 cycles as follows: $30 \mathrm{~s}$ for denaturation at $94^{\circ} \mathrm{C}, 2 \mathrm{~min}$ for annealing at $57^{\circ} \mathrm{C}$ and a final extension step $72{ }^{\circ} \mathrm{C}$ for $2 \mathrm{~min}$ in a Techne TC-512 thermocycler (Techne, Cambridge, UK). The PCR products were analysed by electrophoresis on $1.5 \%$ agarose gel at $70 \mathrm{v}$ for $80 \mathrm{~min}$ in TBE buffer $(1 \times)$, stained in a $0.5 \mathrm{mg} / \mathrm{ml}$ ethidium bromide solution for $15 \mathrm{~min}$ and photographed by CCD Video Camera. The patterns of DNA banding were analysed employing GelCompar software ver. 6 (Applied Math, Belgium).

\section{Statistical analysis}

The chi-square and t-test using SPSS software version 12.0 (SPSS Inc., Chicago, IL, USA) were performed to statistical analysis. A phenogram was constructed by the Unweighted Pair Group Method with Arithmetic Mean (UPGMA) after determination of association coefficients using the simple matching method.

\section{Results}

The antifungal susceptibility and genetic diversity of 50 clinical C. albicans isolates were evaluated by disc diffusion method and RAPD analysis, respectively. The antifungal susceptibilities of $C$. albicans isolated from oral cavity of Iranian $\mathrm{HIV}^{+}$patients are shown in Tables 1 and 2. Results of susceptibility to antifungal drugs were as follows: fluconazole: 29 isolates (58\%) susceptible, 5 isolates (10\%) susceptible-dose dependent or intermediate and 16 isolates (32\%) resistant; ketoconazole: 31 isolates (62\%) susceptible, 5 isolates (10\%) susceptible-dose dependent or intermediate and 14 isolates $(28 \%)$ resistant; amphotericin B: 48 isolates (96\%) susceptible, 2 isolates (4\%) susceptible-dose dependent or intermediate; clotrimazole: 35 isolates $(70 \%)$ susceptible, 8 isolates $(16 \%)$ susceptible-dose dependent or intermediate and 7 isolates (14\%) resistant; flucytosine: 50 isolates (100\%) resistant and nystatin: 50 isolates (100\%) susceptible.

The inhibition zone diameters ranged from $4 \pm 1.8$ to $40 \pm 3.8 \mathrm{~mm}$ (mean value $23.0 \pm 11.7 \mathrm{~mm}$ ) for fluconazole; from $7 \pm 1.0$ to $37 \pm 1.8 \mathrm{~mm}$ (mean value
$24.8 \pm 9.4 \mathrm{~mm}$ ) for ketoconazole; from $14 \pm 08$ to $24 \pm 08 \mathrm{~mm}$ (mean value $17.2 \pm 2.1 \mathrm{~mm}$ ) for amphotericin B; from $7 \pm 4.2$ to $40.0 \mathrm{~mm}$ (mean value $24.8 \pm 8.7 \mathrm{~mm}$ ) for clotrimazole; and from $25 \pm 0.0$ to $33 \pm 0.0 \mathrm{~mm}$ (mean value $26.6 \pm 2.0 \mathrm{~mm}$ ) for nystatin. All isolates were resistant to flucytosine (no inhibition zone was observed).

Candida albicans isolates yielded RAPD profiles with one strong band, with molecular size of 273 bp. Regarding the RAPD-PCR profiles (Fig. 1) and similarity coefficients $\geq 90 \%$; genotypes, containing from 3 to 17 isolates each, encompassed 30 (58.82\%) isolates and 13 (25.49\%) genotypic particular strains. The first cluster, which was the smallest one, composed of ramifications a (ATCC strain) and a' (C32 and C35 isolates), the second cluster composed of ramifications $\mathrm{b}$ and $\mathrm{b}^{\prime}$, and the third cluster (the largest one) composed of ramifications c and $c^{\prime}$, as shown in Fig. 1.

\section{Discussion}

Genetic fingerprinting of C. albicans isolates has widely been studied by several researchers [16]; however, there is limited information about the correlation between the antifungal susceptibility and genetic diversity among C. albicans isolated from HIV-infected individuals [17]. Genetic diversity may occur in the population of C. albicans, revealed by RAPD profiles, because of developed resistance to fluconazole which has previously been described; and we have also observed that at the present study [18]. We used a specific primer pair (CALB1 and CALB2) to amplify a 273 bp region located on 5.8 rRNA gene and identify the $C$. albicans isolates. These results are in line with that of Sharifzadeh et al. [19]. The results of genotyping with RSD12 primer indicated different genetic profiles among $C$. albicans isolates with different antifungal susceptibility patterns. Hamzehee et al. carried out RAPD-PCR for genotyping of $C$. albicans isolates and they found 46 genotypes including 11 clusters with similarity coefficient of $\geq 80 \%$ [9]. Ethtedar-Nejad et al. used PCR-HRM for genotyping of C. albicans isolates and they found this method reliable for accurate identification of Candida species in clinical samples; however,

Table 1 Antifungal susceptibility of oral Candida albicans isolates from HIV-infected patients

\begin{tabular}{llcrr}
\hline Antifungal agents & Drug concentration & Resistance (\%) & Intermediate (\%) & Susceptible (\%) \\
\hline Fluconazole (FCN) & $25 \mu \mathrm{g}$ & 32 & 10 & 58 \\
Clotrimazole (CTM) & $10 \mu \mathrm{g}$ & 14 & 16 & 70 \\
Nystatin (NY) & $100 \mathrm{units}$ & 0 & 0 & 100 \\
Amphotericin B (AMB) & $20 \mu \mathrm{g}$ & 0 & 4 & 96 \\
Ketoconazole (KCA) & $10 \mu \mathrm{g}$ & 28 & 0 & 62 \\
Flucytosine (FY) & $1 \mu \mathrm{g}$ & 100 & 0 \\
\hline
\end{tabular}


Table 2 Antifungal susceptibility of the standard antifungal agents against Candida albicans isolates (mean \pm standard deviation, millimeter)

\begin{tabular}{|c|c|c|c|c|c|}
\hline Genotype & Fluconazole & Ketoconazole & Amphotericin B & Nystatin & Clotrimazole \\
\hline $\mathrm{C} 1$ & $9 \pm 1.2$ & $8 \pm 1.8$ & $20 \pm 1.8$ & $26 \pm 0.2$ & $11 \pm 1.4$ \\
\hline$C 2$ & $11 \pm 0.8$ & $11 \pm 2.4$ & $17 \pm 2.0$ & $25 \pm 0.0$ & $19 \pm 2.2$ \\
\hline C3 & $18 \pm 0.0$ & $25 \pm 0.8$ & $20 \pm 3.2$ & $30 \pm 0.0$ & $36 \pm 0.8$ \\
\hline C4 & $30 \pm 2.2$ & $32 \pm 2.0$ & $14 \pm 0.8$ & $27 \pm 0.0$ & $32 \pm 0.8$ \\
\hline C5 & $35 \pm 2.6$ & $30 \pm 0.4$ & $18 \pm 0.0$ & $26 \pm 0.0$ & $33 \pm 1.0$ \\
\hline C6 & $9 \pm 1.4$ & $7 \pm 1.0$ & $17 \pm 1.0$ & $25 \pm 0.8$ & $10 \pm 2.2$ \\
\hline C7 & $12 \pm 1.8$ & $28 \pm 2.2$ & $17 \pm 2.8$ & $25 \pm 0.4$ & $18 \pm 1.4$ \\
\hline C8 & $33 \pm 1.2$ & $31 \pm 3.6$ & $18 \pm 1.4$ & $25 \pm 0.0$ & $33 \pm 4.2$ \\
\hline C9 & $29 \pm 2.4$ & $32 \pm 0.8$ & $18 \pm 4.2$ & $25 \pm 0.0$ & $25 \pm 2.6$ \\
\hline C10 & $12 \pm 1.4$ & $28 \pm 0.0$ & $18 \pm 2.0$ & $27 \pm 0.0$ & $17 \pm 1.8$ \\
\hline C11 & $5 \pm 0.8$ & $11 \pm 0.2$ & $23 \pm 1.8$ & $25 \pm 0.4$ & $9 \pm 2.6$ \\
\hline $\mathrm{C} 12$ & $37 \pm 1.8$ & $31 \pm 1.2$ & $17 \pm 1.4$ & $25 \pm 0.0$ & $30 \pm 0.8$ \\
\hline C13 & $9 \pm 0.8$ & $28 \pm 0.6$ & $16 \pm 2.2$ & $28 \pm 0.0$ & $8 \pm 3.4$ \\
\hline C14 & $35 \pm 1.0$ & $33 \pm 0.2$ & $18 \pm 0.0$ & $25 \pm 0.0$ & $35 \pm 0.8$ \\
\hline C15 & $8 \pm 2.6$ & $10 \pm 0.8$ & $16 \pm 3.3$ & $26 \pm 0.8$ & $12 \pm 2.4$ \\
\hline C16 & $18 \pm 1.0$ & $28 \pm 0.0$ & $17 \pm 1.0$ & $25 \pm 0.6$ & $28 \pm 0.0$ \\
\hline C17 & $35 \pm 3.2$ & $34 \pm 0.0$ & $15 \pm 5.0$ & $25 \pm 0.0$ & $26 \pm 0.8$ \\
\hline C18 & $39 \pm 0.8$ & $35 \pm 2.8$ & $16 \pm 0.8$ & $26 \pm 1.2$ & $25 \pm 0.6$ \\
\hline C19 & $6 \pm 0.0$ & $15 \pm 0.0$ & $15 \pm 2.0$ & $25 \pm 0.0$ & $9 \pm 3.8$ \\
\hline C20 & $40 \pm 3.8$ & $35 \pm 0.8$ & $16 \pm 3.2$ & $26 \pm 0.0$ & $30 \pm 2.6$ \\
\hline C21 & $32 \pm 2.0$ & $32 \pm 2.4$ & $15 \pm 1.0$ & $25 \pm 0.0$ & $28 \pm 6.2$ \\
\hline C22 & $4 \pm 1.8$ & $7 \pm 3.4$ & $16 \pm 0.8$ & $26 \pm 0.0$ & $17 \pm 0.8$ \\
\hline $\mathrm{C} 23$ & $17 \pm 0.0$ & $25 \pm 0.8$ & $16 \pm 3.4$ & $25 \pm 0.8$ & $25 \pm 1.6$ \\
\hline C24 & $29 \pm 2.2$ & $21 \pm 2.8$ & $15 \pm 3.2$ & $25 \pm 0.8$ & $30 \pm 2.4$ \\
\hline C25 & $18 \pm 1.0$ & $25 \pm 3.2$ & $15 \pm 1.8$ & $27 \pm 0.0$ & $40 \pm 0.0$ \\
\hline C26 & $35 \pm 0.8$ & $32 \pm 2.0$ & $15 \pm 3.6$ & $27 \pm 0.0$ & $23 \pm 3.6$ \\
\hline $\mathrm{C} 27$ & $5 \pm 3.8$ & $8 \pm 4.8$ & $16 \pm 1.8$ & $25 \pm 1.2$ & $7 \pm 4.2$ \\
\hline$C 28$ & $31 \pm 0.6$ & $35 \pm 0.8$ & $17 \pm 0.8$ & $27 \pm 0.8$ & $30 \pm 1.6$ \\
\hline C29 & $30 \pm 1.9$ & $31 \pm 2.0$ & $16 \pm 0.0$ & $25 \pm 0.0$ & $25 \pm 2.6$ \\
\hline C30 & $5 \pm 4.0$ & $29 \pm 1.8$ & $18 \pm 1.0$ & $28 \pm 1.6$ & $13 \pm 0.8$ \\
\hline C31 & $10 \pm 1.2$ & $17 \pm 1.6$ & $16 \pm 4.0$ & $25 \pm 0.0$ & $25 \pm 1.2$ \\
\hline C32 & $28 \pm 3.0$ & $28 \pm 4.2$ & $16 \pm 2.0$ & $25 \pm 0.0$ & $27 \pm 3.8$ \\
\hline C33 & $21 \pm 2.8$ & $14 \pm 2.0$ & $17 \pm 1.4$ & $25 \pm 0.0$ & $24 \pm 2.2$ \\
\hline C34 & $18 \pm 0.0$ & $15 \pm 0.0$ & $16 \pm 0.6$ & $23 \pm 0.0$ & $25 \pm 2.8$ \\
\hline C35 & $27 \pm 1.4$ & $31 \pm 0.8$ & $16 \pm 0.0$ & $26 \pm 0.8$ & $35 \pm 0.8$ \\
\hline C36 & $7 \pm 1.6$ & $9 \pm 0.8$ & $15 \pm 3.4$ & $26 \pm 0.0$ & $17 \pm 4.2$ \\
\hline C37 & $33 \pm 4.8$ & $37 \pm 1.8$ & $17 \pm 2.4$ & $26 \pm 0.0$ & $26 \pm 3.2$ \\
\hline C38 & $4 \pm 3.6$ & $10 \pm 1.0$ & $18 \pm 2.8$ & $28 \pm 0.0$ & $19 \pm 1.4$ \\
\hline C39 & $31 \pm 0.8$ & $30 \pm 2.8$ & $18 \pm 1.4$ & $28 \pm 0.0$ & $32 \pm 4.2$ \\
\hline C40 & $29 \pm 2.4$ & $30 \pm 0.0$ & $16 \pm 4.2$ & $26 \pm 1.4$ & $35 \pm 0.8$ \\
\hline C41 & $34 \pm 1.8$ & $31 \pm 0.6$ & $17 \pm 2.4$ & $26 \pm 1.2$ & $29 \pm 3.2$ \\
\hline C42 & $32 \pm 2.8$ & $34 \pm 2.0$ & $20 \pm 1.0$ & $29 \pm 0.0$ & $31 \pm 2.8$ \\
\hline C43 & $37 \pm 2.4$ & $30 \pm 1.4$ & $18 \pm 3.2$ & $33 \pm 0.0$ & $29 \pm 1.0$ \\
\hline C44 & $29 \pm 3.8$ & $31 \pm 4.0$ & $22 \pm 2.0$ & $31 \pm 0.0$ & $29 \pm 0.0$ \\
\hline C45 & $37 \pm 2.0$ & $29 \pm 3.2$ & $24 \pm 0.8$ & $30 \pm 0.2$ & $33 \pm 0.8$ \\
\hline C46 & $30 \pm 0.0$ & $21 \pm 1.6$ & $17 \pm 2.8$ & $27 \pm 0.0$ & $31 \pm 2.0$ \\
\hline C47 & $8 \pm 2.8$ & $9 \pm 2.4$ & $14 \pm 6.0$ & $31 \pm 1.4$ & $8 \pm 1.6$ \\
\hline C48 & $31 \pm 0.8$ & $33 \pm 1.8$ & $18 \pm 3.2$ & $25 \pm 1.0$ & $30 \pm 0.8$ \\
\hline
\end{tabular}


Table 2 (continued)

\begin{tabular}{llllll}
\hline Genotype & Fluconazole & Ketoconazole & Amphotericin B & Nystatin & Clotrimazole \\
\hline C49 & $29 \pm 3.4$ & $30 \pm 0.8$ & $17 \pm 2.6$ & $30 \pm 0.0$ & $31 \pm 2.0$ \\
C50 & $34 \pm 2.2$ & $33 \pm 3.2$ & $22 \pm 1.8$ & $31 \pm 0.0$ & $30 \pm 0.0$ \\
ATCC & $30 \pm 1.8$ & $30 \pm 2.8$ & $19 \pm 0.8$ & $27 \pm 0.0$ & $35 \pm 0.8$ \\
\hline
\end{tabular}

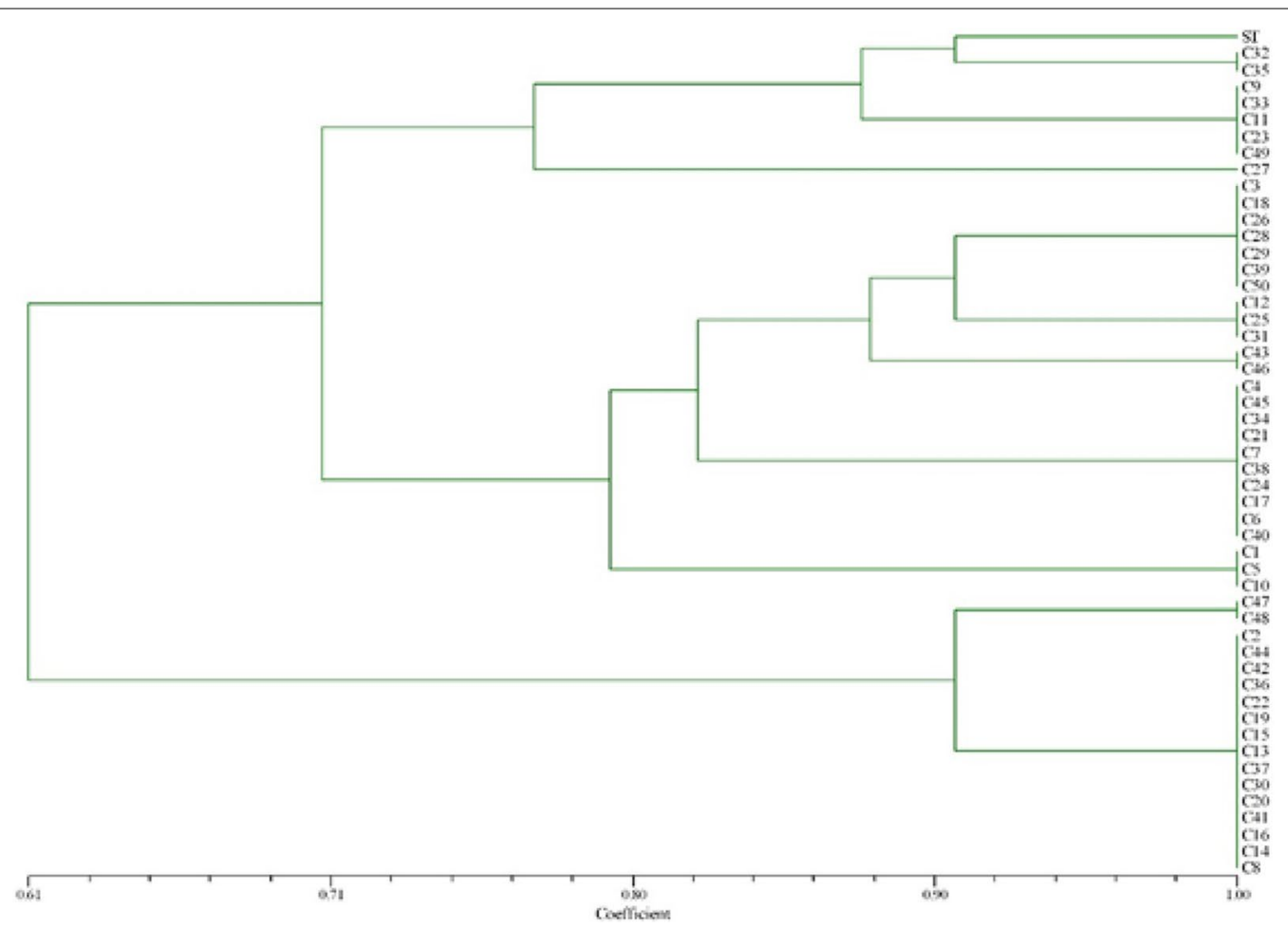

Fig. 1 Dendrogram based on RAPD-PCR data for Candida albicans isolates from oral cavity of Iranian $\mathrm{HIV}^{+}$patients. Similarity coefficients $\geq 90 \%$; containing from 3 to 17 isolates each genotype; encompassed 30 isolates and 13 genotypic particular strains. The first cluster (the smallest one) composed of ramifications a (ATCC strain) and a' (C32 and C35 isolates); the second cluster, ramifications b and b'; and the third cluster (the largest one) composed of ramifications $\mathrm{c}$ and $\mathrm{c}^{\prime}$

this method is more expensive than RAPD method for genotyping in clincal settings [20]. Sun et al. used RSD6 primer and assessed genetic diversity of C. albicans isolated from root canal infection. They found 31 genotypes among 37 isolates [21]. RSD10 and RSD12 primers also were used to determine the clonal variability of $443 C$. albicans isolates collected from 16 HIV-infected individuals. These isolates formed clusters comprising 2 or more strains at similarity coefficient of $\geq 80 \%$ [22]. Our results were also in agreement with those of previous studies.

Fluconazole, despite using drug potency up to $25 \mathrm{mg}$ per disc, showed poor activity against the isolates tested. There are also many studies indicating that fluconazole had less activity against Candida species [23]. Fluconazole resistance, in spite of using drug potency up to $25 \mu \mathrm{g}$ per disc, was $32 \%$. Higher rates of resistance which we observed were not in accordance with those observed in United Kingdom, Brazil, Mexico and other studies which showed lower levels of antifungal drugs resistance [24]. The reason for higher fluconazole resistance could be explained by the fact that azoles, especially fluconazole, have been used for prophylaxis or incomplete treatment of oral candidiasis in HIV-infected patients, therefore, resistance to fluconazole is common during AIDS-related complex [25].

\section{Significance of the study}

C. albicans has been known as one of the most frequent yeasts species associated with infections in 
immunocompromised patients, such as HIV-infected individuals [26]. The findings of the current study revealed genetic diversity and correlation between antifungal susceptibility profiles and the genotype groups of C. albicans isolated from oral cavity of $\mathrm{HIV}^{+}$patients. We also found that amphotericin B and nystatin were the most effective antifungal drugs and fluconazole showed the poorest activity against $C$. albicans.

\section{Limitations}

- Despite all efforts, 50 isolates is not efficient to study and evaluate the genetic relatedness and anti-fungal susceptibility of C. albicans isolated from HIVinfected individuals.

- RAPD is a popular genotyping approach; however, it is not precise enough because of lack of reproducibility. Other genotyping assays are suggested to be implemented.

\footnotetext{
Abbreviations

OPC: Oropharyngeal candidiasis; AIDS: Acquired immunodeficiency syndrome: MDR: Multidrug resistant; RAPD: Randomly amplified polymorphic DNA; HIV: Human immunodeficiency virus.
}

\section{Acknowledgements}

We greatly appreciate all experimental technicians and physicians in Faculty of Medicine, University of Tehran, Tehran, Iran helping us for performing sample collection.

\section{Authors' contributions}

IAT design the research and did the exeriments; BP wrote the first draft and reviewed the manuscript; BNF analyzed the data and supervised the research. All authors read and approved the final manuscript.

\section{Funding}

This study was self-funded.

\section{Availability of data and materials}

All data supporting the results and conclusion of this paper are included within the article.

\section{Declarations}

Ethics approval and consent to participate

This study was reviewed and approved by the ethical committee board, Faculty of medicine, Tehran University of Medical Science, Tehran, Iran (2010/06/12/006). Authorization to perform this investigation at the Imam Khomeini hospital was obtained from the Infectious diseases department of Imam Khomeini hospital, Tehran Univesity of Medical Science.

\section{Consent for publication}

Before taking samples, written informed consent was obtained from each patient at the present study.

\section{Competing interests}

The authors declare that they have no competing interest.

Received: 12 November 2020 Accepted: 23 February 2021 Published online: 10 March 2021

\section{References}

1. Tsui C, Kong EF, Jabra-Rizk MA. Pathogenesis of Candida albicans biofilm. FEMS Pathog Dis. 2016;74(4):ftw018.

2. Swidergall M, Filler SG. Oropharyngeal candidiasis: fungal invasion and epithelial cell responses. PLoS Pathog. 2017;13(1):1-7.

3. Mushi MF, Mtemisika Cl, Bader O, Bii C, Mirambo MM, Groß U, et al. High oral carriage of non-albicans Candida spp. among HIV-infected individuals. Int J Infect Dis. 2016;49:185-8.

4. Khedri S, Santos A, Roudbary M, Hadighi R, Falahati M, Farahyar S, et al. Iranian HIV/AIDS patients with oropharyngeal candidiasis: identification, prevalence and antifungal susceptibility of Candida species. Lett Appl Microbiol. 2018;67(4):392-9.

5. Mane A, Vidhate P, Kusro C, Waman V, Saxena V, Kulkarni-Kale U, et al. Molecular mechanisms associated with fluconazole resistance in clinical Candida albicans isolates from India. Mycoses. 2016;59(2):93-100.

6. Salari S, Khosravi A, Mousavi S, Nikbakht-Brojeni G. Mechanisms of resistance to fluconazole in Candida albicans clinical isolates from Iranian HIVinfected patients with oropharyngeal candidiasis. Journal de mycologie medicale. 2016;26(1):35-41.

7. Kwon YJ, Shin JH, Byun SA, Choi MJ, Won EJ, Lee D, et al. Candida auris clinical isolates from South Korea: identification, antifungal susceptibility, and genotyping. J Clin Microbiol. 2019;57(4):1-11.

8. Dadar M, Tiwari R, Karthik K, Chakraborty S, Shahali Y, Dhama K. Candida albicans-biology, molecular characterization, pathogenicity, and advances in diagnosis and control—an update. Microb Pathog. 2018;117:128-38.

9. Hamzehee S, Kalantar-Neyestanaki D, Afshari SAK, Mousavi SAA. Molecular identification of Candida species, assessment of the antifungal susceptibility and the genetic relationship of Candida albicans isolated from immunocompromised patients in Kerman. Iran Gene Rep. 2019;17:100484.

10. Fothergill AW. Antifungal susceptibility testing: clinical laboratory and standards institute (CLSI) methods. In Interactions of yeasts, moulds, and antifungal agents. 2012; Humana Press. pp. 65-74.

11. Paul S, Kannan I. Molecular identification and antifungal susceptibility pattern of Candida species isolated from HIV infected Patients with candisiasis. Curr Med Mycol. 2019;5(1):21-6.

12. Levinas E, Penati G. Difficile liberté. Paris: Albin Michel; 1995.

13. Liu F, Fan X, Auclair S, Ferguson M, Sun J, Soong L, et al. Sequential dysfunction and progressive depletion of Candida albicans-specific CD4 T cell response in HIV-1 infection. PLoS Pathog. 2016;12(6):e1005663.

14. Izquierdo DF, Barbosa O, Burguete MI, Lozano P, Luis SV, FernandezLafuente $\mathrm{R}$, et al. Tuning lipase B from Candida antarctica $\mathrm{C}-\mathrm{C}$ bond promiscuous activity by immobilization on poly-styrene-divinylbenzene beads. RSC Adv. 2014;4(12):6219-25.

15. Tapia CV, Hermosilla G, Fortes P, Alburquenque C, Bucarey S, Salinas $\mathrm{H}$, et al. Genotyping and persistence of Candida albicans from pregnant women with vulvovaginal candidiasis. Mycopathologia. 2017;182(3-4):339-47.

16. Takahashi Y, Nagata N, Shimbo T, Nishijima T, Watanabe K, Aoki T, et al. Long-term trends in esophageal candidiasis prevalence and associated risk factors with or without HIV infection: lessons from an endoscopic study of 80,219 patients. PLoS ONE. 2015;10(7):e0133589.

17. Clark-Ordóñez I, Callejas-Negrete OA, Aréchiga-Carvajal ET, MouriñoPérez RR. Candida species diversity and antifungal susceptibility patterns in oral samples of HIV/AIDS patients in Baja California. Mex Med mycol. 2017:55(3):285-94.

18. Jain $P$, Khan ZK, Bhattacharya E, Ranade SA. Variation in random amplified polymorphic DNA (RAPD) profiles specific to fluconazole-resistant and -sensitive strains of Candida albicans. Diagn Microbiol Infect Dis. 2001;41(3):113-9.

19. Sharifzadeh A, Khosravi A, Shokri H, Jamnani FA, Hajiabdolbaghi M, Tamami IA. Oral microflora and their relation to risk factors in HIV+ patients with oropharyngeal candidiasis. Journal de mycologie medicale. 2013;23(2):105-12.

20. Nejad EE, Almani PGN, Mohammadi MA, Salari S. Molecular identification of Candida isolates by real-time PCR-high-resolution melting analysis and investigation of the genetic diversity of Candida species. J Clin Lab Anal. 2020;34(10):e23444 
21. Sun J, Qi C, Lafleur MD, Qi Qg. Fluconazole susceptibility and genotypic heterogeneity of oral Candida albicans colonies from the patients with cancer receiving chemotherapy in China. Int J Oral Sci. 2009;1 (3):156-62.

22. Issa SY, Badran EF, AkI KF, Shehabi AA. Epidemiological characteristics of Candida species colonizing oral and rectal sites of Jordanian infants. BMC Pediatr. 2011;11(1):79.

23. Zarnowski R, Sanchez H, Covelli AS, Dominguez E, Jaromin A, Berhardt J, et al. Candida albicans biofilm-induced vesicles confer drug resistance through matrix biogenesis. PLoS Biol. 2018;16(10):e2006872.

24. Arendrup MC, Patterson TF. Multidrug-resistant Candida: epidemiology, molecular mechanisms, and treatment. J Infect Dis. 2017;216(suppl_3):S445-51.

25. Espinel-Ingroff A, Arendrup M, Cantón E, Cordoba S, Dannaoui E, García-Rodríguez J, et al. Multicenter study of method-dependent epidemiological cutoff values for detection of resistance in Candida spp. and Aspergillus spp. to amphotericin B and echinocandins for the Etest agar diffusion method. Antimicrob Agents Chemother. 2017;61(1):e01792-e1816.

26. Terças AL, Marques SG, Moffa EB, Alves MB, de Azevedo CM, Siqueira WL, et al. Antifungal drug susceptibility of candida species isolated from HIVpositive patients recruited at a public hospital in São Luís, Maranhão. Braz Front Microbiol. 2017;8:298.

\section{Publisher's Note}

Springer Nature remains neutral with regard to jurisdictional claims in published maps and institutional affiliations.
Ready to submit your research? Choose BMC and benefit from:

- fast, convenient online submission

- thorough peer review by experienced researchers in your field

- rapid publication on acceptance

- support for research data, including large and complex data types

- gold Open Access which fosters wider collaboration and increased citations

- maximum visibility for your research: over 100M website views per year

At BMC, research is always in progress.

Learn more biomedcentral.com/submissions 